\title{
The Role of Heme Chirality in the Circular Dichroism of Heme Proteins
}

\author{
Robert W. Woody ${ }^{\mathrm{a}}$ and Gennaro Pescitelli ${ }^{\mathrm{b}}$ \\ a Department of Biochemistry and Molecular Biology, Colorado State University, Fort Collins, \\ CO 80523, USA \\ b Dipartimento di Chimica e Chimica Industriale, Università di Pisa, via Risorgimento 35, \\ I-56126 Pisa, Italy
}

Reprint requests to R. W. W.; Fax: 1-970 491 0494, E-mail: robert.woody@ colostate.edu

Z. Naturforsch. 69a, 313 - 325 (2014) / DOI: 10.5560/ZNA.2014-0004

Received December 15, 2013 / revised December 27, 2013 / published online July 15, 2014

Dedicated to Prof. Dr. Jörg Fleischhauer on the occasion of his 75th birthday.

The rotational strength $(R)$ of the Soret transition in sperm-whale myoglobin ( $\mathrm{SW} \mathrm{Mb}$ ), the hemoglobin from Chironomus thummi thummi (CTT Hb), and human hemoglobin $(\mathrm{hHb})$ has been calculated using 20 high-resolution $(<1.5 \AA)$ crystal structures. The intrinsic rotational strength due to heme non-planarity was calculated using $\pi$-electron theory and time-dependent density functional theory (TDDFT). Calculations on model protoporphyrins with a planar nucleus and with various torsional angles for the 2- and 4-vinyl substituents showed maximum $R$ of \pm 0.70 Debye-Bohr magneton ( $1 \mathrm{DBM}=0.9273 \cdot 10^{-38} \mathrm{cgs}$ units). Viewing the heme so that the 2- and 4-vinyls are in a counterclockwise relationship, if a vinyl points toward the viewer, it contributes positively to $R$. Calculations of the intrinsic $R$ for explicit heme geometries of SW Mb, CTT $\mathrm{Hb}$, and hHb gave averages of $0.40 \pm 0.09,-0.44 \pm 0.04$, and $+0.32 \pm 0.11 \mathrm{DBM}$, respectively. Coupling of the Soret transition with aromatic side-chain and peptide backbone transitions was also considered. For SW Mb, the magnitudes of the contributions decreased in the order $R_{\text {int }}>R_{\text {aro }}>R_{\text {pep. }}$. For CTT Hb and $\mathrm{hHB}$, the orders were, respectively, $R_{\text {int }}>R_{\text {pep }}>R_{\text {aro }}$ and $R_{\text {int }}>R_{\text {aro }} \approx R_{\text {pep }}$. Human Hb $\alpha$ chains showed the same trend as CTT Hb. Only in the hHb $\beta$ chains did $R_{\text {aro }}$ predominate, with the order $R_{\text {aro }}>R_{\text {int }}>R_{\text {pep. }}$. The total predicted $R_{\text {tot }}$ for $\mathrm{SW} \mathrm{Mb,} \mathrm{CTT} \mathrm{Hb}$, and hHb averaged $+0.77 \pm 0.10$ $(0.56-0.80),-0.37 \pm 0.12(-0.5)$, and $+0.31 \pm 0.17 \mathrm{DBM}(0.23-0.50)$, respectively. (Values in parentheses are experimental values.) Thus, contrary to the currently accepted view, coupling with aromatic side-chain or peptide transitions is not the dominant factor in the Soret circular dichroism (CD) of these proteins. The Soret CD is dominated by intrinsic CD of the heme chromophore, of which vinyl torsion is the major determinant. This result suggests an explanation for the large effect of heme isomerism on the Soret $\mathrm{CD}$ of $\mathrm{Mb}$ and $\mathrm{Hb}$. Rotation about the $\alpha-\gamma$ axis may be associated with large changes in vinyl torsion and thus substantially alter the intrinsic $\mathrm{CD}$, even reversing its sign.

Key words: Hemoglobin; Myoglobin; Circular Dichroism; Soret Band; Heme Isomerism.

\section{Introduction}

Visible and near-UV circular dichroism (CD) is frequently used to monitor conformational transitions and ligand binding in chromophoric proteins [1-4], of which heme proteins are prominent examples. It is important to understand the source(s) of the CD induced in achiral chromophores bound to proteins, such as the heme in heme proteins and retinal in rhodopsin and bacteriorhodopsin. Does the induced CD primarily result from the binding of a dissymmetrically distorted chromophore (an intrinsic mechanism), or does it arise from coupling of the chro- mophore transitions with the aromatic and peptide chromophores of the protein (an extrinsic mechanism)? For rhodopsin, the case was made for each of these explanations [5-8], but the issue has recently been settled [9] in favor of dissymmetry in the bound chromophore, a twisted polyene, as the dominant factor in the visible/near-UV CD of rhodopsin. For heme proteins, there has been no such controversy. The consensus has been that coupling of the heme with aromatic or peptide chromophores of the protein is largely responsible for the visible/near-UV CD bands, most prominently the Soret (B) band near $400 \mathrm{~nm}$. 
This consensus dates back to the work of Hsu and Woody $[10,11]$, who used the relatively low-resolution structures of sperm-whale myoglobin $(\mathrm{Mb})$ [12] and horse hemoglobin $(\mathrm{Hb})$ [13] available in 1969, together with the CD theory of Tinoco [14] to predict the $\mathrm{CD}$ spectrum of $\mathrm{Mb}$ and $\mathrm{Hb}$. They found that the coupling of the Soret band with aromatic side-chain transitions gives, for $\mathrm{Mb}$, a positive rotational strength $(R)$ of +0.3 Debye-Bohr magnetons (DBM; $1 \mathrm{DBM}=$ $0.9273 \cdot 10^{-38} \mathrm{cgs}$ units), to be compared with the experimental value $[15,16]$ of $\sim 0.5$ DBM. Similarly, calculations on $\mathrm{Hb}$ gave a value of $0.1 \mathrm{DBM}$, comparable with experimental $R$ values of $0.2-0.4$ [15]. In addition, calculations for the visible (Q) bands and the near-UV N and L bands gave rotational strengths with the correct sign and approximate magnitude for these bands. Hsu and Woody [11] also calculated the effects of coupling with the peptide $n \pi *$ and $\pi \pi^{*}$ transitions in $\mathrm{Mb}$, but found them to be negligible.

Hsu and Woody [11] further discussed other potential contributions to the heme $\mathrm{CD}$ : heme nonplanarity and mixing of heme $\pi \pi^{*}$ transitions with iron $d-d$ transitions [17]. At the resolution available in crystal structures in 1970, deviations from planarity of the heme, other than departure of the iron from the heme plane, could not be characterized. This is why Hsu and Woody's calculations focused on the protein chromophores. With respect to potential contributions of iron, Hsu and Woody argued that the relative insensitivity of the Soret CD to the oxidation state, spin state, and ligation of iron is inconsistent with a major role for $d-d$ transitions. This indirect argument was strongly supported by the observation of Ruckpaul et al. [18] that protoporphyrin bound to globin gives $\mathrm{CD}$ spectra similar to those of the native protein.
Fleischhauer and Wollmer [19] calculated the Soret rotational strength of the monomeric $\mathrm{Hb}$ of Chironomus thummi thummi (CTT $\mathrm{Hb})$, considering the aromatic coupling mechanism. This was an important test of the mechanism because the Soret CD of CTT Hb is negative [20], in contrast to that of mammalian $\mathrm{Mb}$ and $\mathrm{Hb}$. Fleischhauer and Wollmer predicted that the aromatic side chains of CTT Hb give rise to a Soret rotational strength of $-0.2 \mathrm{DBM}$, in qualitative agreement with experiment. Subsequently, Strassburger et al. [21] extended these calculations using a $1.4 \AA$-resolution Xray structure [22], including the peptide $n \pi *$ and $\pi \pi^{*}$ transitions, as well as those of asparagine (Asn), glutamine (Gln), aspartic acid (Asp), and glutamic acid (Glu), and the propionate groups of the heme. With the more refined structure the aromatic side-chain contribution to the Soret rotational strength was diminished to $-0.09 \mathrm{DBM}$, but the peptide groups, carboxamide and carboxylate side chains of the protein, and the propionate groups of the heme more than compensated for this, giving a total computed $R=-0.324 \mathrm{DBM}$, in reasonable agreement with the observed value of $-0.5 \mathrm{DBM}$. They concluded that for CTT $\mathrm{Hb}$, the dominant coupling contributions come from the peptide groups. The carboxamide and carboxylate sidechain contributions are negligible, and those of the heme propionates were significant but smaller than those of the aromatic or peptide groups.

More recently, it has been found that the CD spectra of $\mathrm{Mb}$ [23], $\mathrm{Hb}$ [24, 25] and CTT Hb [26] are affected by heme isomerism, that is, the binding of protoheme IX to the globin in two alternative orientations, differing by a $180^{\circ}$ rotation about the $\alpha-\gamma$ methine carbon axis (Fig. 1). Native SW Mb consists of an equilibrium mixture of the A and B isomers in a 11.5: 1 ratio [27]. Aojula et al. [23] found that the Soret band of the dom-

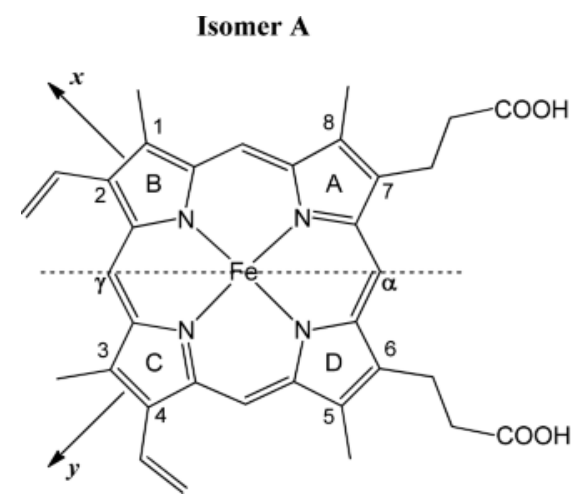

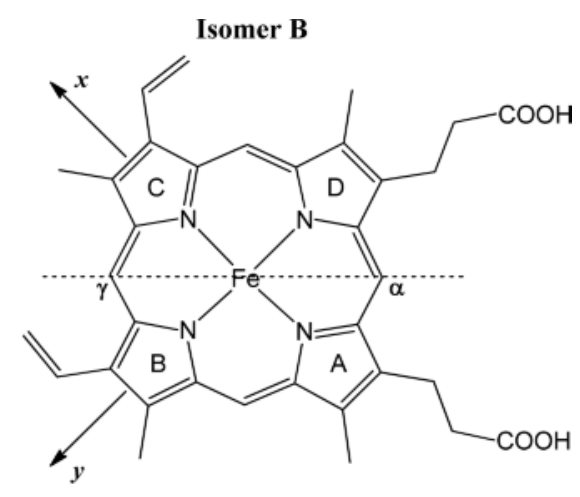

Fig. 1. Heme isomers A and B, which differ by a $180^{\circ}$ rotation about the $\alpha-\gamma$ axis in the protein matrix, viewed from the distal side. The vinyl groups are depicted with $\chi_{2}$ and $\chi_{4}$ equal to $0^{\circ}$ (see Fig. 2) and the numbering system of the periphery of the porphyrin nucleus is shown. 
inant $\mathrm{A}$ isomer has $\Delta \varepsilon=+90 \mathrm{M}^{-1} \mathrm{~cm}^{-1}$, whereas that of isomer B has $\Delta \varepsilon=-7 \mathrm{M}^{-1} \mathrm{~cm}^{-1}$, i. e., it is weakly negative.

The reversal in sign of the Soret CD band between the two isomers is not yet understood. However, it appears incompatible with the position that the coupling of the Soret transition moments with the surrounding chromophores dominates the Soret CD. Hsu [28] showed that for a planar, $\mathrm{D}_{4 h}$-symmetric porphyrin, the coupling-induced rotational strengths of the two degenerate Soret components depend upon the choice of transition moment directions, but the total Soret rotational strength is independent of the directions. Rotation about the $\alpha-\gamma$ axis is equivalent to a rotation of transition moment directions and therefore should not affect the net rotational strength. The presence of the vinyl substituents breaks the degeneracy and thus the net rotational strength is likely to show some variation on heme rotation, but this is unlikely to lead to a change in sign.

The large effect of heme isomerism suggests that the coupling mechanism is not the dominant factor, as has been widely assumed. If the heme itself is chiral, rotation about the $\alpha-\gamma$ axis can readily be envisioned to require a different chiral conformation to fit the binding pocket, and this difference could easily have a substantially different CD spectrum.

In an molecular dynamics (MD) study of heme isomerism [29], simulations of both heme isomers in $\mathrm{Mb}$ were monitored by calculations of the Soret CD spectrum. For the dominant $\mathrm{A}$ isomer, it was found that heme non-planarity accounted for $30 \%$ of the Soret rotational strength, whereas coupling with aromatic transitions gave rise to $40 \%$, and peptide coupling to the remaining $30 \%$. The simulations of the $\mathrm{B}$ isomer did not succeed in reproducing the negative Soret CD band, probably because of an inadequate starting structure.

Although the MD simulations suggested the significance of heme non-planarity for Soret CD, there has been no systematic study of the $\mathrm{CD}$ of $\mathrm{Mb}$ and $\mathrm{Hb}$ taking into account the actual heme geometry as revealed by high-resolution X-ray diffraction structures that are now available. This seemed an appropriate topic for a paper to be dedicated to Jörg Fleischhauer, who has made important contributions to our understanding of the $\mathrm{CD}$ of heme proteins, of proteins more generally, and indeed to the quantum chemistry of a wide range of molecules.

\section{Methods}

\section{Intrinsic Heme Rotational Strengths}

The transition dipole moments and transition charge densities for the Soret band were calculated by $\pi$ electron molecular orbital (MO) theory in the PariserParr-Pople approximation (PPP method) [30-32]. $\pi$ electron calculations have been very successful in predicting the CD spectra of chiral conjugated systems [33]. The 'standard' parameters of Weiss et al. [34] were used. The heme $\pi$-electron system was treated as a porphyrin dianion, including the two vinyl substituents, giving a total of $28 \pi$-centers and $30 \pi$ electrons. Configuration interaction included the 32 lowest energy singly excited configurations, with orbital energy differences up to $\sim 9 \mathrm{eV}$. Electric dipole transition moments were calculated in both the dipole length and dipole velocity approximations. Two-center contributions were neglected in the former case. Slater orbitals with exponents calculated from Slater's rules [35] were utilized in evaluating the gradient and angular momentum operators.

Time-dependent density functional theory (TDDFT) calculations [36] were run with Gaussian09 [37]. For consistency with PPP calculations, the porphyrin dianion was considered. The Coulomb-attenuated hybrid B3LYP functional (CAM-B3LYP) [38] and Ahlrichs triple- $\zeta$ split-valence basis set (TZVP) [39] were employed, including 16 excited states.

Calculations of the heme rotational strength as a function of vinyl torsional angles utilized an idealized porphyrin nucleus with $\mathrm{D}_{4 h}$ symmetry, with bond lengths and bond angles based upon Hoard et al. [40]. The bond lengths assumed for the vinyl substituents were $1.47 \AA$ for the $\mathrm{C}_{\mathrm{p} \beta}-\mathrm{C}_{\mathrm{v} \alpha}$ bond $\left(\mathrm{C}_{\mathrm{p} \beta}\right.$ denotes the $\beta$-carbon of the pyrrole to which the vinyl is attached and $\mathrm{C}_{\mathrm{v} \alpha}$ the $\alpha$-carbon of the vinyl group, see Fig. 2)

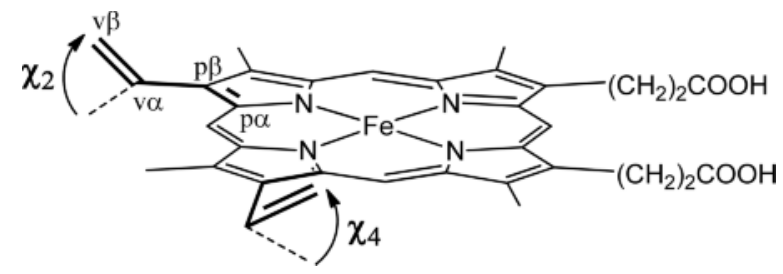

Fig. 2. Definition of dihedral angles $\chi_{2}$ and $\chi_{4}$ describing the conformation of the vinyl groups. The dashed lines represent the cisoid orientations with $\chi_{2}$ and $\chi_{4}=0^{\circ}$; positive angles are indicated by the curved arrows. Heme isomer $\mathrm{A}$ is represented viewed from the distal side. 
and $1.34 \AA$ for the $\mathrm{C}_{\mathrm{v} \alpha}-\mathrm{C}_{\mathrm{v} \beta}$ bond. The $\mathrm{C}_{\mathrm{p} \beta}-\mathrm{C}_{\mathrm{v} \alpha}$ bond was assumed to bisect the exterior angle of the pyrrole ring at $\mathrm{C}_{\mathrm{p} \beta}$, and the $\mathrm{C}_{\mathrm{p} \beta} \mathrm{C}_{\mathrm{v} \alpha} \mathrm{C}_{\mathrm{v} \beta}$ bond angle was assumed to be $120^{\circ}$. The 2 - and 4-vinyls were rotated independently over $180^{\circ}$ at $10^{\circ}$ intervals, and the remaining conformations were generated by mirror symmetry. The zero for $\chi_{2(4)}$, the dihedral angle defined by atoms $\mathrm{C}_{\mathrm{p} \alpha} \mathrm{C}_{\mathrm{p} \beta} \mathrm{C}_{\mathrm{v} \alpha} \mathrm{C}_{\mathrm{v} \beta}$, where $\mathrm{C}_{\mathrm{p} \beta}$ is $\mathrm{C}_{2(4)}$ in Figure 2, corresponds to a cisoid relationship with the $\mathrm{C}_{\mathrm{p} \alpha}-\mathrm{C}_{\mathrm{p} \beta}$ bond of the pyrrole to which the vinyl is attached (Fig. 1).

For the calculation of the intrinsic rotational strength of the hemes in heme proteins, the heme geometry was taken from X-ray structures. All structures used had a resolution of $1.5 \AA$ or better. The input structures for TDDFT calculations were obtained from $\mathrm{X}$-ray structures by geometry optimizations of the hydrogen atoms only, at the B3LYP/6-31G(d) level.

The contributions of coupling between the heme Soret transitions and transitions in the aromatic side chains and peptide groups were calculated according to the equation

$$
\begin{aligned}
& R_{i 0 a}=-\frac{2 \pi}{h c\left(v_{b}^{2}-v_{a}^{2}\right)} \\
& \cdot \sum_{j, b} v_{a} v_{b} V_{i 0 a, j 0 b}\left(\mathbf{R}_{j}-\mathbf{R}_{i}\right) \cdot \boldsymbol{\mu}_{j 0 b} \times \boldsymbol{\mu}_{i 0 a}-\frac{2}{h\left(v_{b}^{2}-v_{a}^{2}\right)} \\
& \cdot \sum_{j, b} \operatorname{Im} V_{i 0 a, j 0 b}\left(\boldsymbol{\mu}_{i 0 a} \cdot \mathbf{m}_{j b 0} v_{a}+\boldsymbol{\mu}_{j 0 b} \cdot \mathbf{m}_{i a 0} v_{b}\right)
\end{aligned}
$$

based upon Tinoco's first-order perturbation theory [14]. Here, $R_{i 0 a}$ is the rotational strength of the transition $0 \rightarrow a$ in group $i$ (the Soret transition in the heme in the present case), whereas $\boldsymbol{\mu}_{i 0 a}$ and $\mathbf{m}_{i 0 a}$ are, respectively, the electric and magnetic dipole transition moments of this transition; $\boldsymbol{\mu}_{j 0 b}$ and $\mathbf{m}_{j 0 b}$ are, respectively, the electric and magnetic dipole transition moments of the transition $0 \rightarrow b$ in aromatic or peptide group $j ; v_{a}$ and $v_{b}$ are, respectively, the frequencies of transition $0 \rightarrow a$ in heme $i$ and transition $0 \rightarrow b$ in aromatic or peptide group $j ; V_{i 0 a ; j 0 b}$ is the energy of interaction between the transition charge densities for transition $0 \rightarrow a$ in heme $i$ and transition $0 \rightarrow b$ in aromatic or peptide group $j$. The summations are to be taken over all transitions $0 \rightarrow b$ in all aromatic and peptide groups $j$.

The first summation in (1) describes coupling of electric dipole transition moments in the heme with the electric dipole transition moments in the other groups. This is Kirkwood's [41] coupled oscillator contribution. The second summation results from coupling of the electric dipole transition moment in the heme with the magnetic dipole transition moments in the aromatic and peptide groups, and vice versa. This is the $\mu-\mathrm{m}$ term discussed by Schellman [42]. The interaction energy between transition charge densities, $V_{i 0 a ; j 0 b}$, was calculated by the monopole [14] (distributed dipole) approximation. This approximation is superior to the point-dipole approximation that is sometimes used. It takes the finite extension of the chromophores into account, which is important when interchromophoric distances are comparable to the dimensions of the chromophores. In addition, it is applicable to dipoleforbidden transitions such as the peptide $n \pi^{*}$ transition. A set of charges, $\rho_{i s 0 a}$, are located at points $\mathbf{R}_{i s}$ such that the electric dipole transition moment for the transition $0 \rightarrow a$ is given by

$$
\boldsymbol{\mu}_{i 0 a}=\sum_{s} \rho_{i s 0 a} \mathbf{R}_{i s} .
$$

The interaction energy of transition densities for transitions $0 \rightarrow a$ in group $i$ and $0 \rightarrow b$ in group $j$ is then given by Coulomb's law for the pairwise interactions of the two sets of transition monopoles:

$$
V_{i 0 a ; j 0 b}=\sum_{s} \sum_{t} \rho_{i s 0 a} \rho_{j t 0 b} /\left|\mathbf{R}_{i s 0 a}-\mathbf{R}_{j t 0 b}\right| .
$$

The method for determining the monopole charges and positions has been described in [14]. For $\pi \pi^{*}$ transitions, the monopole positions correspond to the atomic centers of the $\pi$ system, or to points above and below the plane of the $\pi$ system. The monopoles for $\pi \pi^{*}$ in the heme and aromatic side chains were placed at the atomic centers. The monopole charges were evaluated from the transition density at each atomic center [14]. Monopoles for the peptide group were placed as described by Woody [43]. Their charges were calculated as described by Woody and Sreerama [44]. The monopole parameters for the carboxylate group were generated by the same procedures.

In previous calculations $[10,11,19,21]$ of the perturbation terms (1), the $\boldsymbol{\mu}$-m term was only considered for the $n \pi *$ transition of the peptide groups, which is magnetically allowed. The magnetic dipole transition moments of $\pi \pi$ transitions were neglected. For a $\pi \pi^{*}$ transition in a planar chromophore, it is always possible to find an origin about which the magnetic dipole 
transition moment vanishes [45]. For chromophores of high symmetry, e.g., the benzene ring of phenylalanine (Phe) and unsubstituted or symmetrically substituted porphyrins, this origin is determined by symmetry. However, for tyrosine (Tyr), tryptophan (Trp), and histidine (His), the choice of origin that leads to a vanishing magnetic dipole transition moment is not clear. In the heme, vinyl substituents and deviations from planarity shift the proper origin from the center of the ring in a way that will vary with the porphyrin conformation. In the present case, the magnetic dipole transition moments were calculated from MO theory for each chromophore, relative to an appropriate center as the origin. In the case of the peptide and carboxylate groups, the origin was chosen at the carbonyl carbon, and the magnetic dipole transition moment about that origin was taken to be zero for $\pi \pi^{*}$ transitions [44].

The aromatic side-chain transitions of Phe, Tyr, and Trp were included in the calculations, using methods and parameters described previously [44, 46-48]. $\pi$ MO calculations for His used the GROMOS96 geometry [49] and the variable- $\beta$ parameterization $[50,51]$. Two sets of parameters were required for His: one for the neutral imidazole group, applied to HisA (with the tautomeric proton on $\mathrm{N}_{\delta 1}$ ) and HisB (with the tautomeric proton on $\mathrm{N}_{\varepsilon 2}$ ), the other for the protonated imidazole, used for HisH and His1. (His1, with the imidazole ring coordinated to the heme iron, was considered equivalent to a protonated HisH.) As shown below, the state of protonation and tautomerism has a minimal effect on the results. Therefore, all His residues were considered to be unprotonated and in HisA tautomers, except for the proximal His.

MO calculations by the PPP method using the dipole length approximation generally overestimate the magnitude of the electric dipole transition moment [52]. In our calculations, we have scaled the electric dipole transition moments and the transition monopoles by a factor of $\mu_{\exp } / \mu_{\text {theor }}$, where $\mu_{\exp }$ is the observed transition moment magnitude (or that calculated from the geometric mean of the dipole length and dipole velocity oscillator strengths [52]) and $\mu_{\text {theor }}$ is the magnitude calculated from MO theory. This factor was not applied to the magnetic dipole transition moment or the angular momentum matrix element.

Three peptide transitions - one $n \pi^{*}$ and two $\pi \pi^{*}$ $\left(\mathrm{NV}_{1}\right.$ and $\left.\mathrm{NV}_{2}\right)$ - were considered, using Clark's transition moment magnitudes and directions $\left(\mathrm{NV}_{1}=\right.$ $-55^{\circ}, \mathrm{NV}_{2}=+61^{\circ}$ ) for $\mathrm{N}$-acetylglycine [53] for the $\pi \pi^{*}$ transitions. Since the electric dipole transition moments and monopoles for these $\pi \pi^{*}$ transitions are empirical, no scaling factor has been applied. Peptide $n \pi *$ transition monopole charges and the magnetic moment were calculated using INDO/S wave-functions [54] and the monopoles were placed in a quadrupolar arrangement about the carbonyl group as described previously [44, 48]. The amide transition parameters are given at the website of N. Sreerama [48].

For the carboxylate group, two $n \pi^{*}$ and two $\pi \pi^{*}$ $\left(\mathrm{NV}_{1}\right.$ and $\left.\mathrm{NV}_{2}\right)$ transitions were considered. The transitions were positioned at $198\left(\mathrm{n}_{1} \pi^{*}\right), 194\left(\mathrm{n}_{2} \pi^{*}\right), 166$ $\left(\mathrm{NV}_{1}\right)$, and $128\left(\mathrm{NV}_{2}\right) \mathrm{nm}$. The wavelength of the $\mathrm{NV}_{1}$ transition was based upon the experimental data of Snyder et al. [55]. Other transition energies are based upon ZINDO/S [54] calculations on the acetate ion. Similarly, dipole transition moments and monopole charges were based upon the ZINDO/S results, except for the $\mathrm{NV}_{1}$ electric dipole transition moment magnitude, which was taken from the experimental data of Clark [53] for the carboxyl group of $\mathrm{N}$-acetylglycine. This value was compared with the ZINDO/S result to derive a scale factor $(0.8154)$ used to correct the $\mathrm{ZINDO} / \mathrm{S}$ value for the $\mathrm{NV}_{2}$ transition dipole moment magnitude. The transition dipole moment directions for the carboxylate are determined by symmetry to be along $\left(\mathrm{NV}_{1}\right)$ or perpendicular to $\left(\mathrm{NV}_{2}\right)$ the two-fold axis.

\section{Results and Discussion}

\section{Effect of Vinyl Torsions}

Calculations of the rotational strength of an idealized porphyrin with varying torsional angles for the vinyl groups revealed several general features. It must be stressed that with an idealized planar porphyrin nucleus, rotational strength can only arise from the (twisted) vinyl groups.

(i) If either vinyl group has a torsional angle of $0^{\circ}\left(180^{\circ}\right)$ or $90^{\circ}$ (defined as shown in Fig. 2), that group does not contribute to the rotational strength. If $\chi_{2,4}=0^{\circ}\left(180^{\circ}\right)$, the vinyl group is fully conjugated with the porphyrin nucleus, but its contributions to the $\boldsymbol{\nabla}$ or $\boldsymbol{\mu}$ matrix elements are in the porphyrin plane and those to the $\mathbf{r} \times \boldsymbol{\nabla}$ matrix element are perpendicular to the plane. If $\chi_{2,4}=90^{\circ}$, the vinyl group is not conjugated to 
(a)

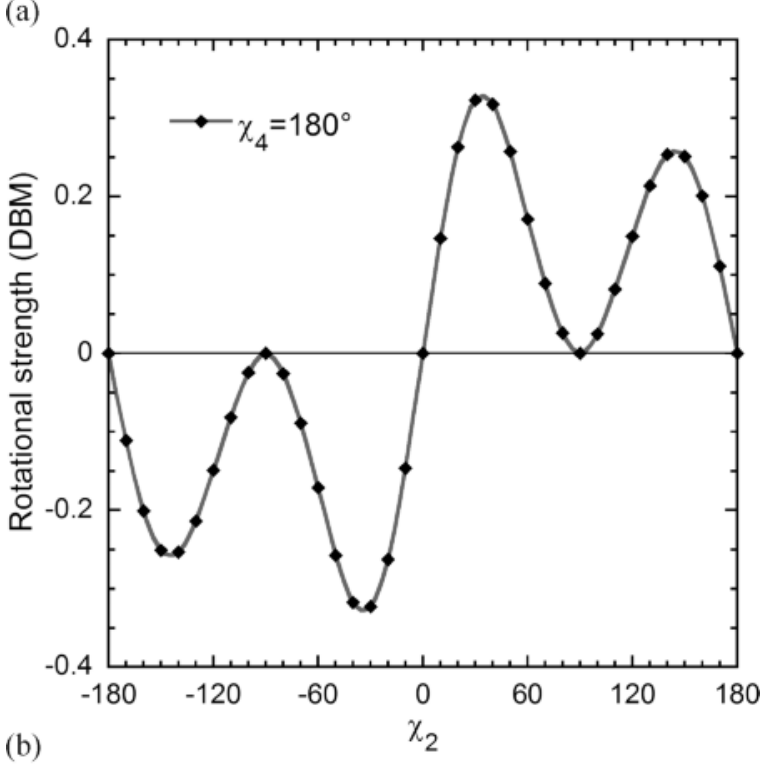

(b)

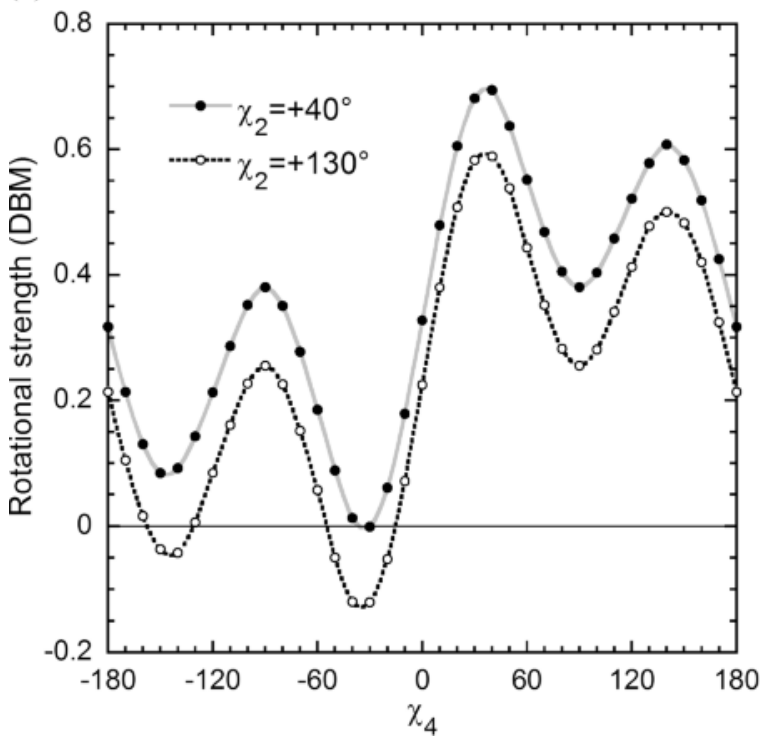

Fig. 3. (a) Intrinsic rotational strength of a model protoporphyrin IX as a function of $\chi_{2}$ for a fixed values of $\chi_{4}=180^{\circ}$. (b) Intrinsic rotational strength of a model protoporphyrin IX as a function of $\chi_{4}$ for fixed values of $\chi_{2}$. Solid circles with solid curve, $\chi_{2}=+40^{\circ}$; open circles with dashed curve, $\chi_{2}=+130^{\circ}$

the porphyrin nucleus and contributes to neither the $\boldsymbol{\nabla}(\boldsymbol{\mu})$ or $\mathbf{r} \times \boldsymbol{\nabla}$ matrix elements. It follows that if both vinyls have $\chi=0^{\circ}\left(180^{\circ}\right)$ or $90^{\circ}$, or if one has $\chi=0^{\circ}\left(180^{\circ}\right)$ and the other has $\chi=90^{\circ}$, the rotational strength of the porphyrin vanishes. (ii) If both the 2- and 4-vinyl groups have positive torsional angles (as shown in Fig. 2, with $0^{\circ}<$ $\chi_{2(4)}<180^{\circ}$ ), the Soret band has a positive rotational strength. Conversely, if both the vinyl groups have a negative torsional angle, the rotational strength is negative. If one views the porphyrin from the side in which the 2- and 4-vinyls appear in counter-clockwise order, as in Figure 1a, and the vinyl groups point toward the viewer, the Soret band will be positive.

(iii) Figure 3 a shows the intrinsic rotational strength of protoporphyrin as a function of $\chi_{2}$ with $\chi_{4}=180^{\circ}$. For $\chi_{2}>0$, the rotational strength is positive with a maximum at $\chi_{2}=40^{\circ}$, a weaker maximum at $\chi_{2}=130^{\circ}$, and it vanishes at $\chi_{2}=90^{\circ}$. For $\chi_{2}<$ $0^{\circ}$, the rotational strength is negative.

(iv) Figure $3 \mathrm{~b}$ shows the rotational strength as a function of $\chi_{4}$ with $\chi_{2}=40^{\circ}$ (cisoid) and with $\chi_{2}=$ $130^{\circ}$ (transoid). The maximum rotational strength occurs at $\chi_{4}=40^{\circ}$ in both cases, with a somewhat smaller maximum at $\chi_{4}=140^{\circ}$. In addition, the cisoid vinyls give $a \sim 20 \%$ larger rotational strength. The maximal rotational strengths are $0.695 \mathrm{DBM}$ for $\left(\chi_{2}, \chi_{4}\right)=\left(40^{\circ}, 40^{\circ}\right)$ and 0.589 for $\left(130^{\circ}, 40^{\circ}\right)$.

(v) If $\chi_{2}$ and $\chi_{4}$ are opposite in sign, the sign of the rotational strength depends upon the relative strengths of the 2- and 4-vinyl contributions. If $\chi_{2} \sim 0^{\circ}\left(180^{\circ}\right)$ or $90^{\circ}$ and $\chi_{4}$ is significantly different from any of these values, the sign will be determined by $\chi_{4}$, i.e., it will be positive for $\chi_{4}>0$ and negative for $\chi_{4}<0$. Figure 3 shows the Soret rotational strength as a function of $\chi_{4}$ (negative) for $\chi_{2}=40^{\circ}$ and $130^{\circ}$. For $\chi_{2}>0^{\circ}, \chi_{4}<0^{\circ}, R$ has maximum absolute values of 0.380 at $\left(40^{\circ},-90^{\circ}\right)$ and -0.380 at $\left(90^{\circ},-40^{\circ}\right)$. As expected, the magnitude of the Soret band is generally smaller when $\chi_{2}$ and $\chi_{4}$ are opposite in sign.

\section{Intrinsic Rotational Strength of Heme in Heme \\ Proteins}

MO calculations were performed for the heme in 20 high-resolution protein structures, including those of sperm whale myoglobin ( $\mathrm{SW} \mathrm{Mb}$ ), hemoglobin from Chironomus thummi thummi (CTT Hb), and human hemoglobin $(\mathrm{hHb})$ obtained from the Protein Data Bank [56]. Additionally, TDDFT calculations were performed on two selected structures from the same se- 


\begin{tabular}{|c|c|c|c|c|c|}
\hline Protein & $\mathrm{PDB}^{\mathrm{a}}$ & Ref. & $R_{\text {int }}(\mathrm{DBM})^{\mathrm{b}}$ & $\chi_{2}(\operatorname{deg})^{\mathrm{c}}$ & $\chi_{4}(\operatorname{deg})^{\mathrm{c}}$ \\
\hline \multirow[t]{4}{*}{ SWMbCO } & $1 \mathrm{~A} 6 \mathrm{G}$ & [65] & 0.403 & 143 & 178 \\
\hline & $1 A 6 G^{\mathrm{d}}$ & [65] & 0.793 & 143 & 178 \\
\hline & 1BZR & {$[66]$} & 0.436 & 142 & 172 \\
\hline & 1JW8 & [67] & 0.397 & 144 & 179 \\
\hline \multirow[t]{2}{*}{$\mathrm{SWMbO}_{2}$} & $1 \mathrm{~A} 6 \mathrm{M}$ & [65] & 0.341 & 141 & 179 \\
\hline & $2 \mathrm{Z6S}$ & [68] & 0.594 & 148 & -178 \\
\hline \multirow[t]{2}{*}{ SWMb } & $1 \mathrm{~A} 6 \mathrm{~N}$ & [65] & 0.303 & 140 & -176 \\
\hline & $1 \mathrm{BZP}$ & [66] & 0.409 & 139 & 173 \\
\hline SWMbIm ${ }^{\mathrm{e}}$ & 1U7R & [67] & 0.367 & 149 & 180 \\
\hline \multirow[t]{4}{*}{$\mathrm{SWMbH}_{2} \mathrm{O}$} & $1 \mathrm{~A} 6 \mathrm{~K}$ & [65] & 0.207 & 144 & -175 \\
\hline & 1BZ6 & [66] & 0.432 & 141 & 176 \\
\hline & $1 B Z 6^{\mathrm{f}}$ & [66] & 0.095 & - & - \\
\hline & $1 \mathrm{U} 7 \mathrm{~S}$ & [67] & 0.368 & 145 & -180 \\
\hline $\mathrm{MbCN}$ & $2 \mathrm{JHO}$ & [69] & 0.505 & 136 & 171 \\
\hline CTT $\mathrm{HbH}_{2} \mathrm{O}$ & $1 \mathrm{ECA}$ & [22] & -0.461 & -40 & -g \\
\hline CTT Hb & $1 \mathrm{ECD}$ & [22] & -0.485 & -33 & $-\mathrm{g}$ \\
\hline CTT HbCN & $1 \mathrm{ECN}$ & [22] & -0.372 & -50 & -g \\
\hline \multirow[t]{2}{*}{ CTT HbCO } & $1 \mathrm{ECO}$ & [22] & -0.456 & -40 & $-g$ \\
\hline & $1 E C O^{\mathrm{d}}$ & [22] & -0.303 & -40 & -g \\
\hline $\mathrm{hHbO}_{2} \alpha$ & 2DN1 & [70] & 0.679 & 143 & 143 \\
\hline$\beta^{\mathrm{h}}$ & 2DN1 & [70] & -0.041 & -39 & 160 \\
\hline hHb deoxy $\alpha_{1}$ & 2DN2 & [70] & 0.625 & 142 & 148 \\
\hline$\alpha_{2}$ & 2DN2 & [70] & 0.527 & 153 & 141 \\
\hline$\beta_{1}{ }^{\mathrm{h}}$ & $2 \mathrm{DN} 2$ & [70] & 0.548 & 144 & 149 \\
\hline$\beta_{2}$ & 2DN2 & [70] & 0.281 & 150 & 149 \\
\hline $\mathrm{hHb} \operatorname{CO} \alpha$ & 2DN3 & [70] & 0.371 & 146 & 144 \\
\hline$\beta$ & 2DN3 & [70] & 0.083 & 178 & 156 \\
\hline$\alpha$ & 1IRD & [71] & 0.358 & 147 & 145 \\
\hline$\beta$ & 1IRD & [71] & 0.135 & 178 & 153 \\
\hline
\end{tabular}

Table 1. Intrinsic rotational strengths of hemes.

PDB [56] code for protein structure.

b $R_{\text {int }}=$ intrinsic rotational strength of the heme. DBM=Debye-Bohr magneton, $1 \mathrm{DBM}=$ $0.9273 \cdot 10^{-38} \mathrm{cgs}$ units.

c Torsional angle about the bond connecting the 2(4)-vinyl group and the porphyrin nucleus. $\chi=0^{\circ}$ corresponds to the vinyl group cis to the $\alpha-\beta$ bond of the pyrrole to which the vinyl is attached.

d TDDFT calculations, in italics, dipole-length gauge.

e $\mathrm{Im}=$ imidazole.

${ }^{\mathrm{f}}$ Calculation for a mesoporphyrin-substituted Mb. Omitting the vinyl groups mimics a porphyrin in which all substituents are saturated.

g In CTT Hb, the 4-vinyls are not well-defined in the electron density map [22] and are therefore omitted in the calculation.

h Three transitions were predicted in the Soret region, with a total oscillator strength comparable to that obtained with the other hemes. All three transitions were included in the calculation of $R_{\text {int }}$ and of the coupling contributions.

ries. Table 1 shows the calculated rotational strengths for the heme Soret band for Mb. It is clear that the intrinsic rotational strength is significant for all of the proteins considered.

The largest body of data is for myoglobin, for which 12 structures were considered. The average intrinsic Soret rotational strength $\left(R_{\text {int }}\right)$ for these 12 proteins is $0.397 \pm 0.093$ DBM (Tab. 2). Table 1 also shows the vinyl torsional angles, $\chi_{2}$ and $\chi_{4}$, for Mb. It will be noted that $\chi_{4}$ is very close to $\pm 180^{\circ}$ in all cases and thus, as noted above, the intrinsic rotational strength will be dominated by $\chi_{2}$, which is near $140^{\circ}$, for which $R_{\text {int }}$ is expected to be sizeable. There is greater variation in the calculated rotational strengths than would be expected from the small variation in vinyl torsional angles. This is attributable to variation in other types of heme planarity, such as ruffling, doming, propellering, etc. [57].

MO calculations were also performed for SW $\mathrm{MbH}_{2} \mathrm{O}$ (PDB 1BZ6) in which the vinyl groups were deleted. The rotational strength is predicted to decrease from 0.432 to $0.095 \mathrm{DBM}$. Thus, the vinyl 
Table 2. Average rotational strengths.

\begin{tabular}{lrrrr}
\hline Protein & $R_{\text {int }}{ }^{\mathrm{a}}$ & $R_{\text {aro }}{ }^{\mathrm{b}}$ & \multicolumn{1}{c}{$R_{\text {pep }}{ }^{\mathrm{c}}$} & \multicolumn{1}{c}{$R_{\text {tot }}{ }^{\mathrm{d}}$} \\
\hline $\mathrm{Mb}$ & 0.397 & 0.243 & 0.130 & 0.771 \\
& \pm 0.093 & \pm 0.045 & \pm 0.040 & \pm 0.102 \\
$\mathrm{CTT} \mathrm{Hb}$ & -0.443 & -0.041 & 0.120 & -0.365 \\
& \pm 0.043 & \pm 0.080 & \pm 0.011 & \pm 0.115 \\
$\mathrm{hHb} \alpha$ & 0.512 & 0.037 & 0.211 & 0.764 \\
& \pm 0.130 & \pm 0.064 & \pm 0.035 & \pm 0.162 \\
$\mathrm{hHb} \beta$ & 0.201 & -0.336 & 0.106 & -0.028 \\
& \pm 0.202 & \pm 0.140 & \pm 0.065 & \pm 0.359 \\
$\mathrm{hHb} \alpha_{2} \beta_{2}$ & 0.322 & -0.164 & 0.151 & 0.310 \\
& \pm 0.106 & \pm 0.070 & \pm 0.027 & \pm 0.165 \\
\hline
\end{tabular}

${ }^{\text {a }} R_{\text {int }}=$ intrinsic rotational strength of the heme (DBM)

b $R_{\text {aro }}=$ contribution of coupling with aromatic side-chain transitions (DBM)

${ }^{\mathrm{c}} R_{\text {pep }}=$ contribution of coupling with peptide backbone and heme propionate side chains (DBM)

${ }^{\mathrm{d}} R_{\mathrm{tot}}=$ total calculated rotational strength $(\mathrm{DBM})$

groups are responsible for $\sim 80 \%$ of the intrinsic rotational strength in myoglobin. This result is consistent with experimental data on myoglobin reconstituted with heme in which the vinyls are saturated to methyl or ethyl (mesoheme) groups. The Soret rotational strength of these modified Mbs is reduced by $\sim 15 \%-30 \%$ relative to the protoheme-containing native $\mathrm{Mb}[25,58]$.

The intrinsic rotational strengths of the heme Soret band for CTT $\mathrm{Hb}$ are negative (Tab. 1). The average over the four structures is $-0.443 \pm 0.043$ (Tab. 2). According to Steigemann and Weber [22], the 4-vinyl group in CTT Hb does not have a preferred location in the crystal structure. The negative value of $R_{\text {int }}$ is expected from our model calculations because $\chi_{2} \sim$ $-40^{\circ}$ and there is no 4-vinyl contribution, so it was omitted in our calculations. Steigemann and Weber did provide coordinates for the 4-vinyl group, assigning the atoms zero weight. Using these coordinates, $\chi_{4} \sim$ $-63^{\circ}$. We performed calculations including both vinyl groups and obtained an average $R_{\text {int }}=-0.603 \pm 0.039$. The larger negative $R_{\text {int }}$ when the second vinyl is included is in line with our model calculations, although the model considering both vinyls is not realistic.

In human hemoglobin, the $\alpha$-chain exhibits intrinsic rotational strengths similar to those of $\mathrm{SW} \mathrm{Mb}$, with an average $R_{\text {int }}=0.512 \pm 0.130$ DBM (Tab. 2). The average rotational strength is somewhat larger than for SW Mb because both $\chi_{2}$ and $\chi_{4}$ are near $140^{\circ}$, giving nearly maximal $R_{\text {int }}$. The $\beta$-chains show the largest variability of the systems studied, with $R_{\text {int }}$ ranging from -0.041 to $+0.548 \mathrm{DBM}$ (Tab. 1 ), and a nearly two-fold difference between the two non-equivalent $\beta$ chains of deoxyHb. The average $R_{\text {int }}=0.201 \pm 0.202$, so averaging the three ligation states of $\mathrm{Hb}$ is not meaningful. This is consistent with the fact that each ligation state has a distinct pattern of $\left(\chi_{2}, \chi_{4}\right)$.

The two structures considered for TDDFT calculations were a myoglobin (MbCO, 1A6G structure) and a hemoglobin (CTT HbCO, 1ECO structure). In both cases, rotational strengths computed with TDDFT and PPP for the Soret band had the same sign (positive for myoglobin and negative for CTT hemoglobin) and order of magnitude (Tab. 1). This consistency confirms the accuracy of MO calculations based on the PPP model in the current case. One reason for the good performance of the PPP model is that, based on orbital and population analysis of TDDFT results, all excitations contributing to the calculated Soret transitions involve only $\pi$-type Kohn-Sham orbitals, with no participation of $n$ orbitals and $n-\pi^{*}$ excitations.

\section{Coupling of the Heme Soret Transition with Aromatic Side-Chain Transitions and Peptide Transitions}

Prior theoretical studies of heme protein CD have identified coupling with aromatic side-chain [10, 11, 19] or with peptide backbone [21] transitions as the dominant factor in determining the Soret rotational strength. For myoglobin, the contributions of coupling with aromatic transitions (Tab. 3) are relatively uniform, with an average of $R_{\text {aro }}=0.243 \pm$ 0.045 DBM. CTT Hb shows more variability, ranging from -0.123 to $+0.087 \mathrm{DBM}$, with an average of $-0.041 \pm 0.080 \mathrm{DBM}$. Human $\mathrm{Hb} \alpha$ chains also show considerable variability in $R_{\text {aro }}$, ranging from -0.073 to 0.120 . Interestingly, the extreme values are for the non-equivalent $\alpha$ chains of deoxy $\mathrm{Hb}$. The resulting average (Tab. 2) is $0.037 \pm 0.064$. Hb $\beta$ chains have more uniform negative $R_{\text {aro }}$ values, averaging $-0.336 \pm 0.140 \mathrm{DBM}$. Therefore, the $\mathrm{Hb} \beta$ chain is the only heme protein chain in our study for which $R_{\text {aro }}$ has a larger magnitude than $R_{\text {int }}$.

Why is $R_{\text {aro }}$ negative for the $\beta$ chains, whereas, with one exception, it is positive for the $\alpha$ chains? Much of the difference arises from two homologous positions, both near the heme group. Tyr $\alpha 42$ contributes 0.041 DBM, whereas its homolog Phe $\beta 41$ contributes $-0.155 \mathrm{DBM}$. For Phe $\alpha 98, R_{\text {aro }}$ is $-0.043 \mathrm{DBM}$, whereas for Phe $\beta 103$ it is $-0.236 \mathrm{DBM}$. These two cases account for a difference of nearly 0.4 DBM. 


\begin{tabular}{|c|c|c|c|c|c|}
\hline Protein & PDB & $R_{\text {int }}{ }^{\mathrm{a}}$ & $R_{\text {aro }}{ }^{\mathrm{b}}$ & $R_{\text {pep }}{ }^{\mathrm{c}}$ & $R_{\mathrm{tot}}^{\mathrm{d}}$ \\
\hline \multirow[t]{3}{*}{ SWMbCO } & $1 \mathrm{~A} 6 \mathrm{G}$ & 0.403 & 0.229 & 0.156 & 0.788 \\
\hline & 1BZR & 0.436 & 0.225 & 0.133 & 0.794 \\
\hline & $1 \mathrm{JW} 8$ & 0.397 & 0.189 & 0.110 & 0.696 \\
\hline \multirow[t]{2}{*}{$\mathrm{SWMbO}_{2}$} & $1 \mathrm{~A} 6 \mathrm{M}$ & 0.341 & 0.298 & 0.112 & 0.751 \\
\hline & $2 \mathrm{Z} 6 \mathrm{~S}$ & 0.594 & 0.217 & 0.174 & 0.985 \\
\hline \multirow[t]{2}{*}{ SWMb } & $1 \mathrm{~A} 6 \mathrm{~N}$ & 0.303 & 0.257 & 0.141 & 0.701 \\
\hline & $1 \mathrm{BZP}$ & 0.409 & 0.268 & 0.017 & 0.694 \\
\hline SWMbIm & 1U7R & 0.367 & 0.227 & 0.125 & 0.720 \\
\hline \multirow[t]{3}{*}{$\mathrm{SWMbH}_{2} \mathrm{O}$} & $1 \mathrm{~A} 6 \mathrm{~K}$ & 0.207 & 0.312 & 0.138 & 0.658 \\
\hline & $1 \mathrm{BZ6}$ & 0.432 & 0.246 & 0.126 & 0.804 \\
\hline & $1 \mathrm{U} 7 \mathrm{~S}$ & 0.368 & 0.156 & 0.170 & 0.694 \\
\hline $\mathrm{MbCN}$ & $2 \mathrm{JHO}$ & 0.505 & 0.299 & 0.161 & 0.966 \\
\hline CTT $\mathrm{HbH}_{2} \mathrm{O}$ & $1 \mathrm{ECA}$ & -0.461 & -0.123 & 0.116 & -0.468 \\
\hline СТT Hb & $1 \mathrm{ECD}$ & -0.485 & -0.092 & 0.121 & -0.456 \\
\hline CTT HbCN & $1 \mathrm{ECN}$ & -0.372 & 0.087 & 0.106 & -0.180 \\
\hline CTT HbCO & $1 \mathrm{ECO}$ & -0.456 & -0.036 & 0.137 & -0.356 \\
\hline $\mathrm{hHbO}_{2} \alpha$ & 2DN1 & 0.679 & 0.024 & 0.273 & 0.975 \\
\hline$\beta$ & 2DN1 & -0.041 & -0.569 & 0.057 & -0.553 \\
\hline$\alpha_{2} \beta_{2}$ & 2DN1 & 0.319 & -0.273 & 0.165 & 0.212 \\
\hline hHb deoxy $\alpha_{1}$ & 2DN2 & 0.625 & 0.120 & 0.198 & 0.944 \\
\hline$\alpha_{2}$ & 2DN2 & 0.527 & -0.073 & 0.222 & 0.676 \\
\hline$\beta_{1}$ & 2DN2 & 0.548 & -0.252 & 0.096 & 0.393 \\
\hline$\beta_{2}$ & 2DN2 & 0.281 & -0.157 & 0.233 & 0.358 \\
\hline$\alpha_{2} \beta_{2}$ & 2DN2 & 0.495 & -0.090 & 0.187 & 0.593 \\
\hline hHb CO $\alpha$ & 2DN3 & 0.371 & 0.072 & 0.191 & 0.634 \\
\hline$\beta$ & 2DN3 & 0.083 & -0.308 & 0.080 & -0.146 \\
\hline$\alpha_{2} \beta_{2}$ & 2DN3 & 0.227 & -0.119 & 0.135 & 0.244 \\
\hline$\alpha$ & 1IRD & 0.358 & 0.043 & 0.171 & 0.590 \\
\hline$\beta$ & 1IRD & 0.135 & -0.392 & 0.064 & -0.193 \\
\hline$\alpha_{2} \beta_{2}$ & 1IRD & 0.247 & -0.175 & 0.118 & 0.190 \\
\hline
\end{tabular}

Table 3. Intrinsic and coupling contributions to soret rotational strength.

${ }^{\text {a }} R_{\text {int }}=$ intrinsic rotational strength of the heme (DBM)

${ }^{\mathrm{b}} R_{\text {aro }}=$ contribution of coupling with aromatic side-chain transitions (DBM)

${ }^{\mathrm{c}} R_{\text {pep }}=$ contribution of coupling with peptide backbone and heme propionate side chains (DBM)

${ }^{\mathrm{d}} R_{\mathrm{tot}}=$ total calculated rotational strength (DBM)

The effect of His protonation and tautomerism on the aromatic contributions was assessed by comparing results for three models for myoglobin (1A6G): (i) all His, except for the proximal His, are unprotonated and in the HisA form; (ii) all His, except for the proximal His, are unprotonated and in the HisB form; (iii) the His are assigned protonation and tautomeric states according to a detailed examination of nuclear magnetic resonance (NMR) and X-ray and neutron diffraction data [59]. $R_{\text {aro }}$ for these three models is $0.229,0.219$, and 0.225 , respectively. Thus, the effect of protonation and tautomeric states is minimal, with a maximum difference of 5\% between the models. We have chosen to assign all His residues, except for the proximal His, as unprotonated and in the HisA tautomer, as this shows slightly better agreement with the detailed model.

Our values for $R_{\text {aro }}$ can be compared with previously published studies for myoglobin and hemoglobin [11] and for CTT $\mathrm{Hb}[19,21]$. Hsu and Woody [11] reported $R_{\text {aro }}=0.306 \mathrm{DBM}$, calculated for a $1.5 \AA$ structure of $\mathrm{SW} \mathrm{MbH}_{2} \mathrm{O}$ [12]. Our results for the three $\mathrm{SW} \mathrm{MbH} \mathrm{Mb}_{2} \mathrm{O}$ structures give an average of $0.238 \pm 0.064 \mathrm{DBM}$. Hsu and Woody considered only 12 of the 23 aromatics nearest the heme, used a lower resolution structure, and considered an unsubstituted porphyrin, so the agreement is reasonable.

In the case of CTT $\mathrm{Hb}$, a more direct comparison is possible because Strassburger et al. [21] used a $1.4 \AA$ structure [22], on which PDB files 1ECA, $1 \mathrm{ECD}, 1 \mathrm{ECN}$, and $1 \mathrm{ECO}$ are based. Strassburger et al. did not specify which form of the protein they studied, but it appears that it was CTT deoxyHb (1ECD) because a comparison of the $R_{\text {aro }}$ they report for six aromatic side chains with our results shows a small rootmean-square deviation of 0.015 DBM and this derivative gave a total $R_{\text {aro }}=-0.078 \mathrm{DBM}$, in good agreement with our value of -0.092 DBM. 
The peptide contributions are very similar for $\mathrm{Mb}$ and CTT $\mathrm{Hb}$, with average values of 0.13 and $0.12 \mathrm{DBM}$. The $\mathrm{Hb} \alpha$ and $\beta$ chains show significantly higher and lower values, respectively, with averages of 0.21 and $0.11 \mathrm{DBM}$. The fact that all four types of proteins have comparable positive $R_{\text {pep }}$ values is attributable to the close similarity of the protein fold in these cases.

Hsu and Woody [11] predicted negligible contributions for the peptide $n \pi *$ and $\pi \pi^{*}\left(\mathrm{NV}_{1}\right)$ transition in $\mathrm{Mb}$ (0.003 DBM). They used older amide transition parameters [60] and a lower resolution structure [12], neglected two more distant $\alpha$-helical segments, and assumed a planar unsubstituted porphyrin structure.

Strassburger et al. [21] predicted a significant negative peptide contribution in CTT Hb $(-0.194$ DBM or, if one includes the heme propionate groups as we do here, $-0.238 \mathrm{DBM})$. This disagrees with our value of $0.121 \mathrm{DBM}$ for CTT Hb. As noted above, the similarity in chain folding of all the proteins studied here would suggest a uniform sign for $R_{\text {pep }}$, supporting a positive value for $\mathrm{CTT} \mathrm{Hb}$. The discrepancy is probably attributable to a significant difference in the $\mathrm{NV}_{1}$ transition moment direction and to our inclusion of the $\mathrm{NV}_{2}$ transition.

Strassburger et al. [21] also considered the coupling of the heme Soret transition with the electronic transitions of the propionate side chains of the heme. They reported a contribution of $-0.087 \mathrm{DBM}$ from the 7-propionate of the heme in CTT deoxyHb. Nagai et al. [25] have suggested that heme propionate groups may play a significant role in inducing heme rotational strengths. We have calculated the contributions of these propionate groups to the Soret rotational strengths of the 20 heme proteins studied in our work. We find these contributions to be small but not negligible. The average values for $\mathrm{Mb}, \mathrm{CTT}$ $\mathrm{Hb}, \mathrm{hHb} \alpha, \mathrm{hHb} \beta$, and $\mathrm{hHb} \alpha_{2} \beta_{2}$ are $-0.024 \pm 0.039$, $-0.041 \pm 0.004,+0.040 \pm 0.027,+0.016 \pm 0.043$, and $+0.028 \pm 0.016$, respectively. The propionate contributions have been included with those of the peptide groups in Table 3 .

The total rotational strength for $\mathrm{SW} \mathrm{Mb}$ (Tab. 2 and 3) averages $0.771 \pm 0.102 \mathrm{DBM}$, of which $R_{\text {int }}$ constitutes $51 \%, R_{\text {aro }} 32 \%$, and $R_{\text {pep }} 17 \%$. Experimentally, the Soret rotational strength of myoglobin has been estimated [11] as $0.5 \pm 0.05 \mathrm{DBM}$ from the data of Beychok [61] and Willick et al. [16]. Blauer et al. [62] reported rotational strengths for $\mathrm{MbH}_{2} \mathrm{O}$ and
$\operatorname{MbIm}(\mathrm{Im}=$ imidazole) averaging 0.71 DBM. These values need to be corrected upward because the experimental values refer to the equilibrium mixture of heme isomers A and B [27] whereas the calculated values refer to the dominant $A$ isomer. Aojula et al. [23] inferred $\Delta \varepsilon_{\max }=+90 \mathrm{M}^{-1} \mathrm{~cm}^{-1}$ for the $\mathrm{A}$ form and $-7 \mathrm{M}^{-1} \mathrm{~cm}^{-1}$ for the $\mathrm{B}$ form. Assuming the equilibrium ratio of $\mathrm{A}: \mathrm{B}$ is $11.5: 1$ [27], the factor for correcting the equilibrium $R_{\text {tot }}$ value to that for the A-form is 1.10 , giving corrected values of $0.55-0.78 \mathrm{DBM}$. Thus, our $R_{\text {tot }}$ values are in good agreement with experiment.

For CTT $\mathrm{Hb}, R_{\mathrm{tot}}$ is predicted to range from -0.180 to $-0.468 \mathrm{DBM}$ (Tab 3), with an average of $-0.365 \pm$ 0.117 DBM. $R_{\text {int }}$ and $R_{\text {aro }}$ are negative and $R_{\text {pep }}$ is positive, with $R_{\text {int }}$ corresponding to $121 \%$ of $R_{\text {tot }}$ and $R_{\text {aro }}$ to only $11 \%$. Strassburger et al. [21] quote an experimental value of $-0.5 \mathrm{DBM}$, presumably (see above) for the deoxy form. Our calculations predict a value of -0.456 for the deoxy form and -0.468 for the $\mathrm{HbH}_{2} \mathrm{O}$ form, in reasonable agreement with experiment.

$\mathrm{CTT} \mathrm{Hb}$ also exhibits heme isomerism, with a $3: 2$ ratio of major to minor isomers [26]. The major isomer is the form found in the crystal [22] and has the opposite orientation to that found in myoglobin, i.e., the major form of CTT Hb is isomer B (Fig. 1). In the case of CTT $\mathrm{Hb}$, the CD of the individual isomers has not been reported, so we can only compare our calculated value for the major isomer with that for the equilibrium mixture. The similarity of these values, together with the relatively high content $(40 \%)$ of the minor isomer at equilibrium, suggests a relatively small difference in the $\mathrm{CD}$ of the two isomers in CTT $\mathrm{Hb}$, in contrast to $\mathrm{SW} \mathrm{Mb} \mathrm{[23].}$

Comparison of the results for the individual $\alpha$ and $\beta$ side chains of hemoglobin is problematic. The predicted values for $\alpha$ chains range from 0.590 to $0.975 \mathrm{DBM}$, averaging $0.764 \pm 0.162 \mathrm{DBM}$. The predicted values are much more positive than the value of $0.3 \pm 0.25$ DBM estimated by Hsu and Woody [11] from experimental data $[15,63,64]$. The experimental studies demonstrated that the $\mathrm{CD}$ of reconstituted $\mathrm{Hb}$ tetramer differs significantly from that of the sum of the individual subunits, implying conformational changes and associated CD changes in the subunits upon association.

The predicted values for the $\beta$ subunit have a very large range of values for $R_{\text {tot }}$, from -0.553 to $0.393 \mathrm{DBM}$, rendering the average value of $-0.028 \pm$ 
0.359 DBM of dubious significance. It is more reasonable to treat the deoxy form $\left(\left\langle R_{\text {tot }}\right\rangle=0.376 \pm 0.018\right)$ and the liganded forms $\left(\left\langle R_{\mathrm{tot}}\right\rangle=-0.297 \pm 0.182\right)$ separately. Two experimental studies of $\beta$ subunits [15, 63 ] agree that the $\beta$ subunit has a less positive Soret rotational strength than the $\alpha$ subunit and that the Soret band is a positive couplet, in contrast to the simple positive band of the $\alpha$ subunit. However, the couplet reported by Nagai et al. is nearly symmetric with a very small net positive $R$, whereas that given by Geraci and Li has a strongly dominant positive component. In any case, experimental data do not support our prediction of a net negative $R_{\text {tot }}$ for the liganded $\beta$ chains, $\mathrm{Hb} \beta \mathrm{O}_{2}$ and $\mathrm{Hb} \beta \mathrm{CO}$. As with the $\alpha$ chains, this may be attributable to differences in the conformation of isolated $\beta$ chains and $\beta$ chains in the $\alpha_{2} \beta_{2}$ tetramer.

For $\mathrm{Hb}$ tetramers, $R_{\mathrm{tot}}$ is predicted to range from 0.190 to 0.593 , with an average of $0.310 \pm 0.165 \mathrm{DBM}$. As with the $\beta$ chains, there is a clear difference between deoxyHb (0.593 DBM) and the liganded Hb's, with an $R_{\text {tot }}$ of $0.215 \pm 0.022$ DBM. Nagai et al. [24] have chromatographically separated recombinant hHB expressed in E. coli into three components that have $12 \%, 51 \%$, and $86 \%$ isomer B, as determined by NMR spectroscopy. They have measured the CD spectra of each fraction in the deoxyHb, $\mathrm{HbO}_{2}$, and $\mathrm{HbCO}$ forms. By taking difference CD spectra, they were able to deduce the CD spectra of the A and B isomers in these three ligation states. From their published data, we estimate the rotational strengths for the $\mathrm{A}$ isomer to be $0.50 \mathrm{DBM}$ for deoxyHb, 0.23 $\mathrm{DBM}$ for $\mathrm{HbO}_{2}$, and

[1] M. R. Mauk, F. I. Rosell, and A. G. Mauk, Biochemistry 46, 15033 (2007).

[2] A. M. Arutyunyan, V. B. Borisov, V. I. Novoderezhkin, J. Ghaim, J. Zhang, R. B. Gennis, and A. M. Konstantinov, Biochemistry 47, 1752 (2008).

[3] R. Schweitzer-Stenner, A. Hagarman, D. Verbaro, and J. B. Soffer, Meth. Enzymol. 466, 109 (2009).

[4] F. Hache, J. Photochem. Photobiol. A. Chem. 204, 137 (2009).

[5] A. S. Waggoner and L. Stryer, Biochemistry 10, 3250 (1971).

[6] A. Kropf, B. P. Whittenberger, S. P. Goff, and A. S. Waggoner, Exp. Eye Res. 17, 591 (1973).

[7] B. Honig, P. Kahn, and T. G. Ebrey, Biochemistry 12, 1637 (1973).
0.27 DBM for HbCO. (The Soret rotational strengths for the B isomers are 0.16, 0.00, and -0.21 DBM, respectively.) The values for the A-form can be compared with our predicted rotational strengths: 0.59, 0.21 , and $0.22 \mathrm{DBM}$, respectively. The agreement is very good.

In the three heme proteins studied here, inherent chirality of the heme dominates the rotational strength of the Soret band. This is also the case for three of the four heme protein chains, the exception being human $\mathrm{Hb} \beta$.

As noted earlier, it is difficult to understand the reversal of the sign of the Soret CD band between heme isomers if coupling with protein chromophores is predominant. Our results suggest an explanation for the large effect of heme isomerism in $\mathrm{SW} \mathrm{Mb}$, which is essentially that proposed by Moench [58]. Heme chirality makes a contribution comparable to (we find it to be larger than) that of coupling with the aromatic side chains and peptide groups, and the two contributions are of the same sign in the A isomer. Reversal of the heme orientation leads to an approximate inversion of the heme chirality and the sign of the intrinsic heme $\mathrm{CD}$, but has little or no effect on the coupling. The intrinsic and coupling contributions are opposite in sign in the $\mathrm{B}$ isomer and, because $R_{\text {int }}$ is dominant, the sign of the Soret $\mathrm{CD}$ is reversed.

\section{Acknowledgement}

We thank Prof. Masako Nagai for communicating her results before publication.

[8] N. Fishkin, N. Berova, and K. Nakanishi, Chem. Record 4, 120 (2004).

[9] G. Pescitelli, N. Sreerama, P. Salvadori, K. Nakanishi, N. Berova, and R. W. Woody, J. Am. Chem. Soc. 130, 6170 (2008).

[10] M. C. Hsu and R. W. Woody, J. Am. Chem. Soc. 91, 3679 (1969).

[11] M. C. Hsu and R. W. Woody, J. Am. Chem. Soc. 93, 3515 (1971).

[12] H. C. Watson, in: Progress in Stereochemistry, Vol. 4 (Eds.: B. J. Aylett and M. M. Harris), Butterworths, London 1969, pp. 299-333.

[13] M. F. Perutz, H. Muirhead, J. M. Cox, and L. C. G. Goaman, Nature 219, 131 (1968).

[14] I. Tinoco, Adv. Chem. Phys. 4, 113 (1962). 
[15] M. Nagai, Y. Sugita, and Y. Yoneyama, J. Biol. Chem. 244, 1651 (1969).

[16] G. E. Willick, G. R. Schonbaum, and C. M. Kay, Biochemistry 8, 3729 (1969).

[17] M. V. Volkenstein, L. T. Metlyaev, and I. S. Milevskaya, Molekul. Biol. (Moscow) 3, 190 (1969).

[18] K. Ruckpaul, H. Rein, and F. Jung, Naturwissenschaften 57, 131 (1970).

[19] J. Fleischhauer and A. Wollmer, Z. Naturforsch. 27b, 530 (1972)

[20] H. Formanek and J. Engel, Biochim. Biophys. Acta 160, 151 (1968).

[21] W. Strassburger, A. Wollmer, H. Thiele, J. Fleischhauer, W. Steigemann, and E. Weber, Z. Naturforsch. 33c, 908 (1978).

[22] W. Steigemann and E. Weber, J. Mol. Biol. 127, 309 (1979).

[23] H. S. Aojula, M. T. Wilson, G. R. Moore, and D. J. Williamson, Biochem. J. 250, 853 (1988).

[24] M. Nagai, Y. Nagai, Y. Aki, K. Imai, Y. Wada, S. Nagatomo, and Y. Yamamoto, Biochemistry 47, 517 (2008).

[25] M. Nagai, Y. Nagai, K. Imai, and S. Neya, Chirality 2014, in press, doi:10.1002/chir.22273.

[26] G. N. LaMar, K. M. Smith, K. Gersonde, H. Sick, and M. Overkamp, J. Biol. Chem. 255, 66 (1980).

[27] G. N. LaMar, N. L. Davis, D. W. Parish, and K. M. Smith, J. Mol. Biol. 168, 887 (1983).

[28] M. C. Hsu, Ph.D. thesis, University of Illinois (Urbana, Illinois) 1970.

[29] R. W. Woody, C. Kiefl, N. Sreerama, Y. Lu, Y. Qiu, and J. A. Shelnutt, in: Insulin and Related Proteins - Structure to Function and Pharmacology (Eds.: M. Federwisch, M. L. Dieken, and P. D. Meyts), Kluwer Academic Publishers, Dordrecht 2002, pp. 233-248.

[30] R. Pariser and R. G. Parr, J. Chem. Phys. 21, 466 (1953).

[31] R. Pariser and R. G. Parr, J. Chem. Phys. 21, 767 (1953).

[32] J. A. Pople, Trans. Faraday Soc. 49, 1375 (1953).

[33] N. Harada and S. Kuwahara, in Comprehensive Chiroptical Spectroscopy, Vol. 2 (Eds.: N. Berova, P. L. Polavarapu, K. Nakanishi, and R. W. Woody), Wiley-VCH, Hoboken, NJ 2012, pp. 167-215.

[34] C. Weiss, H. Kobayashi, and M. Gouterman, J. Mol. Spectrosc. 16, 415 (1965).

[35] J. C. Slater, Phys. Rev. 36, 57 (1930).

[36] J. Autschbach, L. Nitsch-Velasquez, and M. Rudolph, Top. Curr. Chem. 298, 1 (2011).

[37] M. J. Frisch, G. W. Trucks, H. B. Schlegel, G. E. Scuseria, M. A. Robb, J. R. Cheeseman, G. Scalmani, V. Barone, B. Mennucci, G. A. Petersson, H. Nakatsuji, M. Caricato, X. Li, H. P. Hratchian, A. F. Izmaylov,
J. Bloino, G. Zheng, J. L. Sonnenberg, M. Hada, M. Ehara，K. Toyota， R. Fukuda，J. Hasegawa， M. Ishida, T. Nakajima, Y. Honda, O. Kitao, H. Nakai, T. Vreven, J. A. Montgomery, Jr., J. E. Peralta, F. Ogliaro, M. Bearpark, J. J. Heyd, E. Brothers, K. N. Kudin, V. N. Staroverov, R. Kobayashi, J. Normand, K. Raghavachari, A. Rendell, J. C. Burant, S. S. Iyengar, J. Tomasi, M. Cossi, N. Rega, J. M. Millam, M. Klene, J. E. Knox, J. B. Cross, V. Bakken, C. Adamo, J. Jaramillo, R. Gomperts, R. E. Stratmann, O. Yazyev, A. J. Austin, R. Cammi, C. Pomelli, J. W. Ochterski， R. L. Martin， K. Morokuma， V. G. Zakrzewski, G. A. Voth, P. Salvador, J. J. Dannenberg, S. Dapprich, A. D. Daniels, Ö. Farkas, J. B. Foresman, J. V. Ortiz, J. Cioslowski, and D. J. Fox, Gaussian09, revision D.01, Gaussian, Inc., Wallingford CT (USA), 2009.

[38] T. Yanai, D. P. Tew, and N. C. Handy, Chem. Phys. Lett. 393, 51 (2004)

[39] A. Schaefer, C. Huber, and R. J. Ahlrichs, J. Chem. Phys. 100, 5829 (1994).

[40] J. L. Hoard, M. J. Hamor, and T. A. Hamor, J. Am. Chem. Soc. 85, 2334 (1963).

[41] J. G. Kirkwood, J. Chem. Phys. 5, 479 (1937).

[42] J. A. Schellman, Accts. Chem. Res. 1, 144 (1968).

[43] R. W. Woody, J. Chem. Phys. 49, 4797 (1968).

[44] R. W. Woody and N. Sreerama, J. Chem. Phys. 111, 2844 (1999).

[45] W. Moffitt, J. Chem. Phys. 25, 467 (1956).

[46] R. W. Woody, Biopolymers 17, 1451 (1978).

[47] I. B. Grishina and R. W. Woody, Faraday Disc. 99, 245 (1994).

[48] N. Sreerama, http:/lamar.colostate.edu/ sreeram 1999.

[49] W. F. v. Gunsteren, S. R. Billeter, A. A. Eising, P. H. Huenenberger, P. Krueger, A. E. Mark, W. R. R. Scott, and I. G. Tironi, Biomolecular Simulations: The GROMOS Manual and User Guide, Hochschulverlag AG an der ETH, Zuerich 1996.

[50] K. Nishimoto and L. S. Forster, Theor. Chim. Acta 3, 407 (1965)

[51] K. Nishimoto and L. S. Forster, Theor. Chim. Acta 4, 155 (1966)

[52] A. E. Hansen, Theor. Chim. Acta 6, 341 (1966).

[53] L. B. Clark, J. Am. Chem. Soc. 117, 7974 (1995).

[54] J. E. Ridley and M. C. Zerner, J. Mol. Spectrosc. 50, 457 (1974)

[55] P. A. Snyder, P. M. Vipond, and W. C. Johnson, Biopolymers 12, 975 (1973).

[56] H. M. Berman, J. Westbrook, Z. Feng, G. Gilliland, T. N. Bhat, H. Weissig, I. N. Shindyalov, and P. E. Bourne, Nucl. Acids Res. 28, 235 (2000).

[57] J. A. Shelnutt, X. Z. Song, J. G. Ma, S. L. Jia, W. Jentzen, and C. J. Medforth, Chem. Soc. Rev. 27, 31 (1998). 
[58] S. J. Moench, Ph.D. thesis, Colorado State University 1986.

[59] C. Kiefl, unpublished work 2001.

[60] R. W. Woody and I. Tinoco, J. Chem. Phys. 46, 4927 (1967).

[61] S. Beychok, in: Poly- $\alpha$-amino Acids (Ed.: G. D. Fasman), Marcel Dekker, New York 1967, pp. 293-337.

[62] G. Blauer, N. Sreerama, and R. W. Woody, Biochemistry 32, 6674 (1993).

[63] G. Geraci and T. K. Li, Biochemistry 8, 1848 (1969).

[64] P. T. Goodall and E. M. Shooter, J. Mol. Biol. 39, 675 (1969).

[65] J. V. K. Chu, J. Berendzen, R. M. Sweet, and I. Schlichting, Biophys.J. 77, 2153 (1999).
[66] G. S. Kachalova, A. N. Popov, and H. D. Bartunik, Science 284, 473 (1999).

[67] D. A. Kondrashov, W. Zhang, R. Aranda, B. Stec, and G. N. Phillips, Proteins 70, 353 (2008).

[68] M. Unno, H. Chen, S. Kusama, S. Shaik, and M. IkedaSaito, J. Am. Chem. Soc. 129, 13394 (2007).

[69] A. Arcovito, M. Benfatto, M. Cianci, S. S. Hasnain, K. Nienhaus, G. U. Nienhaus, C. Savino, R. W. Strange, B. Vallone, and S. Della Longa Proc. Natl. Acad. Sci. USA 104, 6211 (2007).

[70] S.-Y. Park, T. Yokoyama, N. Shibayama, Y. Shiro, and J. R. Tame, J. Mol. Biol. 360, 690 (2006).

71] S.-Y. Park and J. R. H. Tame, unpublished work 2001. 